Atmos. Chem. Phys., 10, 1093-1103, 2010

www.atmos-chem-phys.net/10/1093/2010/

(C) Author(s) 2010. This work is distributed under

the Creative Commons Attribution 3.0 License.

\title{
Fractional release factors of long-lived halogenated organic compounds in the tropical stratosphere
}

\author{
J. C. Laube $^{1,2}$, A. Engel ${ }^{1}$, H. Bönisch ${ }^{1}$, T. Möbius ${ }^{1}$, W. T. Sturges ${ }^{2}$, M. Braß ${ }^{3}$, and T. Röckmann ${ }^{3}$ \\ ${ }^{1}$ Institute for Atmospheric and Environmental Sciences, University of Frankfurt, Frankfurt, Germany \\ ${ }^{2}$ School of Environmental Sciences, University of East Anglia, Norwich, UK \\ ${ }^{3}$ Institute for Marine and Atmospheric Research, Utrecht University, Utrecht, The Netherlands
}

Received: 28 August 2009 - Published in Atmos. Chem. Phys. Discuss.: 28 September 2009

Revised: 12 January 2010 - Accepted: 26 January 2010 - Published: 2 February 2010

\begin{abstract}
Fractional release factors (FRFs) of organic trace gases are time-independent quantities that influence the calculation of Global Warming Potentials and Ozone Depletion Potentials. We present the first set of vertically resolved FRFs for 15 long-lived halocarbons in the tropical stratosphere up to $34 \mathrm{~km}$ altitude. They were calculated from measurements on air samples collected on board balloons and a high altitude aircraft. We compare the derived dependencies of FRFs on the mean stratospheric transit times (the socalled mean ages of air) with similarly derived FRFs originating from measurements at higher latitudes and find significant differences. Moreover a comparison with averaged FRFs currently used by the World Meteorological Organisation revealed the limitations of these measures due to their observed vertical and latitudinal variability. The presented data set could be used to improve future ozone level and climate projections.
\end{abstract}

\section{Introduction}

Many halocarbons are strong greenhouse gases and/or are able to enhance the catalytic decomposition of ozone via the products of their chemical degradation. Moreover, the chemical composition of the stratosphere interacts with its radiative balance and the distribution and abundance of ozone (e.g. Brasseur and Solomon, 1986). The tropical stratosphere

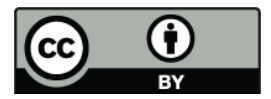

Correspondence to: J. C. Laube (j.laube@uea.ac.uk) is very important for the climate of this planet - e.g. most of the ozone is produced there. Thus it is important to quantify the vertical distributions of halocarbons in this atmospheric region.

Very few non-satellite measurements of halocarbons in the tropical stratosphere have been performed (e.g. Goldan et al., 1980; Schauffler et al., 1993, 1999; Volk et al., 1997; Laube et al., 2008). Due to the elevated tropopause in the tropics (between about 15 and $18 \mathrm{~km}$ depending on the meteorological conditions) aircraft-based investigations such as those of Volk et al. (1997) and Schauffler et al. (1999) were only able to investigate the lower stratosphere there (up to $21 \mathrm{~km})$. Satellite instruments provide higher spatial and temporal coverage but have only limited precision and/or vertical resolution and have also not been able to quantify many halocarbons up to now (e.g. Moore and Remedios, 2008; Allen et al., 2009; Rinsland et al., 2009). Thus whole-air-samples collected on board balloons, which reach high altitudes up to $38 \mathrm{~km}$ represent a unique opportunity for high precision middle stratospheric measurements.

A fractional release factor (FRF) is a relative quantity. It can be described as the inorganic halogen fraction released from a halocarbon at a given location and time in the stratosphere. It is time-independent as long as the general stratospheric circulation and actinic flux spectrum are not changing. Global Warming Potentials (e.g. Daniel et al., 1995) and the semi-empirical calculation of Ozone Depletion Potentials (ODPs; Solomon et al., 1992; Schauffler et al., 1999) are measures of the ability of a trace gas to influence future climate and to deplete stratospheric ozone. FRFs contain timeindependent information on vertical trace gas distributions

Published by Copernicus Publications on behalf of the European Geosciences Union. 
and thus influence the calculation of both measures e.g. via the atmospheric lifetimes or Radiative Forcings assigned to the respective compound (see e.g. Douglass et al., 2008).

For a FRF calculation according to Eq. (1) (taken from Daniel and Velders, 2007) two quantities must be known: the mixing ratio of a compound at a given altitude and the corresponding mixing ratio of the compound when it entered the stratosphere. The former was measured for this work and the latter can be calculated from the mean age of the air (i.e. the mean stratospheric transit time) and tropospheric concentration time series for long-lived compounds. Please note, that our calculations include the assumption that the difference between the entry mixing ratio and measured mixing ratio is all in the inorganic form. In principle, a calculation is also possible for very short lived substances (VSLS), but the corresponding FRFs are highly variable and depend on the season and location of the respective emissions in the troposphere (Ko and Poulet, 2003). For these reasons no FRFs could be calculated for VSLS from the limited available data set for this work.

$f_{i}(x, y, z, t)=\frac{\rho_{i, \text { entry }}-\rho_{i}(x, y, z, t)}{\rho_{i, \text { entry }}}$

$\rho_{i}(x, y, z, t)-$ mixing ratio of the halocarbon at a given stratospheric location $(x, y, z)$ at time $t$

$\rho_{i, \text { entry }}-$ mean initial mixing ratio of the halocarbon in the air parcel when it entered the stratosphere

A number of different methods to derive fractional release factors of halocarbons have been described in the literature. The quantity itself was first defined by Solomon and Albritton (1992) according to Eq. (1). As few stratospheric measurements of halocarbons were available at this time Solomon et al. (1992) used models and a semi-empirical analysis of measured stratospheric profiles for methane and other gases to estimate FRFs. Daniel et al. (1995) combined measurements of air samples originating from the Arctic stratosphere and model calculations to derive FRFs relative to $\mathrm{CFCl}_{3}$ (CFC-11) by assuming that most halocarbons show linear correlations with this compound throughout the stratosphere. Schauffler et al. (2003) and Newman et al. (2006) improved this calculation by deriving the FRFs as a function of mean age of air from aircraft-based observations in the lower stratosphere in middle and high latitudes. Moreover they included the effect of an age spectrum in their calculations which will be explained in the following.

Each stratospheric air parcel can be assumed to consist of a large number of infinitesimally small parcels, which have experienced different transport pathways since crossing the tropical tropopause. Thus, a probability distribution function of transit times to the given location in the stratosphere can be assigned to the air parcel which is the so-called age spectrum (Hall and Plumb, 1994). It describes how the composition of an air parcel is altered by mixing processes with older and newer air parcels. Schauffler et al. (2003) and Newman et al. (2006) used the estimated age spectra to calculate the amount of a halocarbon for a given mean age that would be present without decomposition of the compound in the stratosphere. This amount represents the stratospheric entry mixing ratio $\rho_{i \text {,entry }}$ of the compound for an air parcel taking into account the mixing processes during transport from the tropical tropopause (the entry region) to its location in the stratosphere.

To calculate $\rho_{i, \text { entry }}$ the past tropospheric distributions of the respective trace gas must be known. A number of longer-lived halocarbons are continuously measured by the NOAA-ESRL (National Oceanic Atmospheric Administration - Earth System Research Laboratory) global groundbased network (see http://www.esrl.noaa.gov/gmd/). Globally averaged tropospheric time series can be derived for these compounds on a monthly basis and the data are publicly accessible at the above mentioned internet address. Schauffler et al. (2003) and Newman et al. (2006) used such temporal trends and an age spectra method described by Waugh and Hall (2002) to simulate stratospheric transport and mixing.

The FRF data set derived here includes six CFCs, four HCFCs, three Halons and two longer-lived non-fluorinated Chlorocarbons and uses new data from the middle stratosphere at tropical latitudes, where few data exist for halocarbons. These FRFs could improve calculations of Equivalent Effective Stratospheric Chlorine (EESC; see Newman et al., 2007), a term used to quantify the effects of chlorinated and brominated organic compounds on stratospheric ozone depletion. Moreover, they could be used for the validation of models and thus help to predict future ozone levels and climate. Douglass et al. (2008) for instance showed that those model simulations that include realistic mean age and FRF distributions predict longer atmospheric lifetimes for chlorofluorocarbons.

\section{Analytical section}

The data presented here originate from measurements on air samples collected (a) with three balloon-borne wholeair-samplers launched in June 2005 from Brazil $\left(5^{\circ} 04^{\prime} \mathrm{S}\right.$, $42^{\circ} 52^{\prime} \mathrm{W}$ ) and in October 2006 from Southern France $\left(44^{\circ} \mathrm{N}, 0.4^{\circ} \mathrm{E}\right)$ and (b) during flights of the high altitude aircraft Geophysica between $43^{\circ} \mathrm{N}$ and $22^{\circ} \mathrm{S}$. An overview is given in Table 1. Three cryogenic whole-air-samplers (named BONBON-I, BONBON-II and CLAIRE) are operated by the University of Frankfurt. These samplers are brought into the stratosphere with large balloons launched by the French Space Agency CNES (Centre National d'Etudes Spatiales). To avoid contamination from out-gassing of the balloon or gondola parts (due to the low pressures and high radiation in the stratosphere) BONBON samples are preferentially taken during the slow descent of the balloon if the meteorological conditions permit. The BONBON cryosamplers consist of a Dewar which contains 15 stainless steel 
Table 1. Overview of analysed air samples collected at altitudes above $10 \mathrm{~km}$. Only uncontaminated samples were used for the calculation of FRFs i.e. 31 samples from balloon-borne whole-air-samplers and 42 samples from the Geophysica high altitude research aircraft.

\begin{tabular}{|c|c|c|c|c|c|}
\hline Flight no. & Sampler & Location & Flight date & $\begin{array}{r}\text { No. of } \\
\text { Samples }\end{array}$ & $\begin{array}{l}\text { Sample altitude } \\
\text { range }[\mathrm{km}]\end{array}$ \\
\hline B42 & BII & $\begin{array}{l}\text { Teresina, Brazil, } 5^{\circ} 04^{\prime} \mathrm{S}, \\
42^{\circ} 52^{\prime} \mathrm{W}\end{array}$ & 08 Jun 2005 & 11 & $15-34$ \\
\hline B43 & BI & $\begin{array}{l}\text { Teresina, Brazil, } 5^{\circ} 04^{\prime} \mathrm{S}, \\
42^{\circ} 52^{\prime} \mathrm{W}\end{array}$ & 25 Jun 2005 & 14 & $15-34$ \\
\hline $\mathrm{C} 1$ & CLAIRE & $\begin{array}{l}\text { Aire Sur l'Adour, } 44^{\circ} \mathrm{N}, \\
0.4^{\circ} \mathrm{E}\end{array}$ & 15 Oct 2006 & 6 & $12-28$ \\
\hline $\mathrm{R} 3 \mathrm{a}$ & WAS & $\begin{array}{l}\text { Dubai - Larnaca, } \\
25-33^{\circ} \mathrm{N}, 38-53^{\circ} \mathrm{E}\end{array}$ & 16 Dec 2005 & 6 & $17.2-17.8$ \\
\hline $\mathrm{R} 3 \mathrm{~b}$ & WAS & $\begin{array}{l}\text { Larnaca - } \\
\text { Oberpfaffenhofen, } \\
35-43^{\circ} \mathrm{N}, 14-33^{\circ} \mathrm{E}\end{array}$ & 17 Dec 2005 & 7 & $16.7-17.1$ \\
\hline S3 & WAS & $\begin{array}{l}\text { Survey Indonesia, } \\
8-12^{\circ} \mathrm{S}, 130-134^{\circ} \mathrm{E}\end{array}$ & 23 Nov 2005 & 13 & $15.5-18.3$ \\
\hline S8 & WAS & $\begin{array}{l}\text { Survey South, } \\
13-22^{\circ} \mathrm{S}, 131-134^{\circ} \mathrm{E}\end{array}$ & 06 Dec 2005 & 11 & $13.9-19.7$ \\
\hline $\mathrm{T} 3$ & WAS & $\begin{array}{l}\text { Tapao - Brunei, } \\
5-13^{\circ} \mathrm{N}, 101-115^{\circ} \mathrm{E}\end{array}$ & 11 Nov 2005 & 5 & $12.7-17.5$ \\
\hline
\end{tabular}

containers $(300-500 \mathrm{~mL}$ volume) that are electro-polished inside to provide a smooth and inert surface. The Dewar is filled with liquid neon before the balloon flights and cools to about $27 \mathrm{~K}$. This allows sampling of large amounts of air even at low outside pressures because the containers work as cryopumps (almost all air components are condensed inside). More technical details are given in Schmidt et al. (1987) and Engel (1993). The new cryosampler CLAIRE built in 2006 is based on the same principle, but it was designed to take samples during balloon ascent and can collect 26 samples.

Other air samples were collected with the whole air sampler (WAS) of Utrecht University operated onboard the Geophysica high altitude research aircraft. These samples were collected into evacuated stainless steel containers (two litre volume) using a trace gas free metal bellows pump. Some of these samples showed contaminations most probably caused by a temporal malfunction of the pump used to evacuate the containers. Those samples showing contaminations in two or more long-lived halocarbons were not used for further retrievals.

All whole air samples were analysed in Frankfurt using cryogenic pre-concentration followed by Gas Chromatography with Electron Impact Mass Spectrometric detection (GC-EI-MS). Please refer to Laube et al. (2008) and Kaiser et al. (2006) for further details on sampling and measurement techniques as well as calibration scales. Mixing ratios of $\mathrm{SF}_{6}$ were measured within the workgroup for flight $\mathrm{B} 42$ and by the University of Heidelberg for flights B43 and C1, all using GC-ECD techniques.

\section{Calculation of fractional release factors and error bars}

We calculated FRFs using Eq. (1). The unknown quantity in

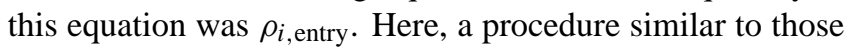
of Schauffler et al. (2003) and Newman et al. (2006) was used to derive it. The applied method was described by Engel et al. (2002) and includes effects from an age spectrum as well as from global tropospheric temporal concentration trends for the calculation of mean age and the propagation of a species without chemical loss. First, for every sample the mean age of air (i.e. the first moment of the age spectrum) was derived from mixing ratios of $\mathrm{SF}_{6}$. These can be used to calculate a mean stratospheric transit time by assigning the mixing ratio observed in the stratosphere to a certain time of the past tropospheric $\mathrm{SF}_{6}$ trend (e.g. Strunk et al., 2000). As the corresponding age spectra cannot be measured directly they were derived from the mean ages via a parameterisation according to Engel et al. (2002) using 0.7 as a fixed ratio of the squared spectral width to the mean age. Subsequently the corrected stratospheric entry mixing ratio was calculated for each compound and sample by assigning mixing ratio distributions to the age spectra via the above mentioned tropospheric time series according to the calculation of total chlorine in Engel et al. (2002). The parameterisation of the age spectra is different to the one used in Schauffler et al. (2003). To test the sensitivity, we re-calculated FRFs for flight B42 using two different ratios (0.5 and 1.25) and found all corresponding changes to be less than 0.02 . Thus we consider the exact parameterisation to have little influence on the FRFs. 
For five compounds no monthly tropospheric trend data was available from NOAA-ESRL: $\mathrm{C}_{2} \mathrm{~F}_{5} \mathrm{Cl}$ (CFC115), $\mathrm{CF}_{2} \mathrm{ClCF}_{2} \mathrm{Cl}$ (CFC-114), $\mathrm{CF}_{3} \mathrm{CFCl}_{2}$ (CFC-114a), $\mathrm{CF}_{2} \mathrm{BrCF}_{2} \mathrm{Br}$ (Halon 2402) and $\mathrm{CHFClCF}_{3}$ (HCFC-124). Thus, a temporal trend was derived via linear regression from the annually averaged mixing ratios back to 1998 which were taken from Table 1-1 of Montzka and Fraser (2003) and Table 1-2 of Clerbaux and Cunnold (2007) (AGAGE, in situ data was used except for Halon 2402: UEA, flasks). The mixing ratios for 2005 derived from these trend functions did not match with the measured mixing ratios originating from air samples collected in the Tropical Tropopause Layer (TTL, i.e. the main stratospheric entrance region) in 2005. This is likely to be caused by differences in absolute calibration scales. However, the FRFs are only fractions i.e. relative values to the entrance mixing ratios. Thus, the trend functions were shifted to match the mixing ratios observed in the TTL using a conversion factor.

No $\mathrm{SF}_{6}$ data was available for the samples collected from the high altitude aircraft (Flights R3, S3, S8 and T3). To assign a mean age of air to these samples a correlation of mean age of air and a tracer was derived for the tropical stratosphere. A polynomial of the form of Eq. (2) best reflected the correlation of mean ages $\Gamma$ and $\mathrm{CF}_{2} \mathrm{Cl}_{2}$ (CFC-12) mixing ratios $\left(\mathrm{MR}_{\mathrm{CFC}-12}\right)$ of the lower stratospheric data resulting from the balloon flights B42 and B43.

$\Gamma=28.71-0.19 \cdot \mathrm{MR}_{\mathrm{CFC}-12}+5.08 \cdot 10^{-5}$

$\cdot\left(\mathrm{MR}_{\mathrm{CFC}-12}\right)^{2}-4.55 \cdot 10^{-7} \cdot\left(\mathrm{MR}_{\mathrm{CFC}-12}\right)^{3}$

Please note, that this function is only valid for the tropical stratosphere in 2005 for air having mean ages below 3.5 years and a CFC-12 mixing ratio range from 545 to 350 ppt. The FRFs were then calculated according to those of the other flights but using the "CFC-12 mean age" instead of $\mathrm{SF}_{6}$.

For the calculation of tropical FRFs all data between $22^{\circ} \mathrm{S}$ and $22^{\circ} \mathrm{N}$ and above potential temperatures of $360 \mathrm{~K}$ were used. These criteria were chosen to include (a) only tropical mixing ratios and (b) the variability of the compounds in the TTL. The six tropical Geophysica samples with mean ages above 1 year were collected on a survey south between 16 and $22^{\circ} \mathrm{S}$ at altitudes between 18 and $20 \mathrm{~km}$ and seem to follow the higher-latitudinal correlations. Considering the high mean ages for the collection altitudes these air masses are very likely to be mainly of extra-tropical origin. Thus the respective samples were not considered for the calculation of tropical FRF-mean-age correlations.

FRF uncertainties (error bars in the Figures) include the $1 \sigma$ measurement uncertainties, the sample instability errors (only for $\mathrm{CCl}_{4}$ and $\mathrm{CH}_{3} \mathrm{CCl}_{3}$ on flight $\mathrm{B} 42$; see Laube et al., 2008 for further details) and the standard deviations of the global mixing ratios averaged over 2001 as provided by NOAA-ESRL (source: http://www.esrl.noaa.gov/ gmd/). They were calculated according to those in Laube et al. (2008). An additional uncertainty originating from interhemispheric mixing ratio gradients was accounted for by adding the average percent difference between the 2001 data from the NOAA-ESRL stations in Tutuila, American Samoa $\left(14.25^{\circ} \mathrm{S}, 170.56^{\circ} \mathrm{W}\right)$ and Mauna Loa, Hawaii, United States $\left(9.54^{\circ} \mathrm{N}, 155.58^{\circ} \mathrm{W}\right)$.

Uncertainties of the mean ages were derived for the flights B42 and B43 only. First the influence of addition and subtraction of the $1 \sigma$ SF6 measurement uncertainty on the mean age was calculated. Second, the mean ages were calculated using different widths of the age spectrum ( 0.5 and 1.25). The error bars were calculated as the sum of those both errors that had the same algebraic sign and can also be found in the figures.

\section{Results and discussion}

The correlation between the mixing ratios of two trace gases that are both long-lived (so-called tracers) is compact in the stratosphere (Plumb and Ko, 1992). But transport barriers, photochemical processes and also latitudinal and seasonal variations in the vertical distributions of tracers cause different correlation curves between these compounds for different stratospheric regions (e.g. Plumb, 1996; Volk et al., 1997; Engel et al., 2002; Waugh and Hall, 2002). Due to the major transport barriers the stratosphere can be subdivided into three regions which show characteristic correlations between the tracers: tropics, mid-latitudes and the polar vortex which forms at high-latitudes around the respective winterpole. The correlations in these regions vary with season. For example Boering et al. (1994) performed stratospheric measurements of $\mathrm{CO}_{2}$ and $\mathrm{N}_{2} \mathrm{O}$ in northern mid-latitudes and found the correlations between these tracers to be seasonally dependent indicating that vertical transport above $20 \mathrm{~km}$ is slower in northern summer than in winter. The highest seasonal variability is observed in polar regions where an isolated vortex forms in winter inside which characteristic correlations are found (e.g. Waugh et al., 1997). In contrast, seasonal correlation changes in the tropical stratosphere are believed to be smaller (Plumb, 2002, 2007) which is why the analysed air samples collected in different seasons in 2005 were combined in one data set here.

To summarise, air masses in similar stratospheric regions have experienced similar transport pathways. This leads to correlations between two long-lived halocarbons that are characteristic for those regions. This can also be observed for FRFs when plotted against the corresponding mean ages of air as shown in Fig. 1 for $\mathrm{CFCl}_{3}$ (CFC-11). In the tropics CFC-11 shows a greater decrease with increasing mean age than at mid-latitudes. The highest FRF differences are observed for mean ages of air between two and five years. Also displayed in Fig. 1 is the mid- and high-latitude correlation derived by Newman et al. (2006) which consists of two functions: a quadratic polynomial to calculate FRFs for low ages of air up to 1.5 years and a cubic polynomial for older 


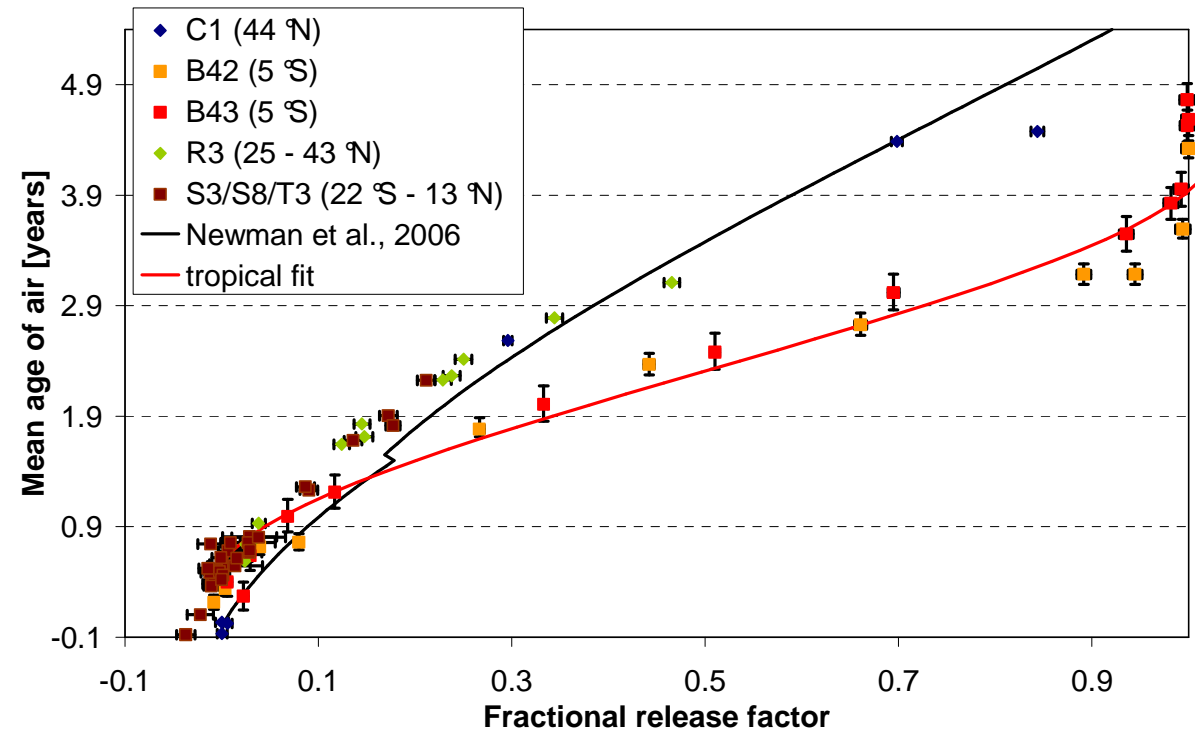

Fig. 1. Fractional release factors (FRFs) and mean ages of air for CFC-11. The mean age is plotted on the y-axis because it increases with altitude. The cold colours (blue and green) represent data of mid-latitudinal origin while the warm colours (orange, red and brown) represent tropical and subtropical data. Small negative values that occur for low ages and FRFs are caused by atmospheric variability and measurement uncertainties. The black curves are the correlation functions derived by Newman et al. (2006) using data from lower stratospheric aircraft observations in middle and high latitudes. The derived mid-latitudinal and subtropical FRFs are comparable to the fit functions of Newman et al. (2006) but the tropical FRFs increasingly differ for older ages.

ages. The derived mid-latitudinal and subtropical FRFs are comparable with the fit functions of Newman et al. (2006) but the tropical FRFs are considerably larger for older ages of air. The faster decomposition of CFC-11 in the tropical stratosphere at higher altitudes is most likely caused by the enhanced radiation relative to regions at higher latitudes. Calculations and model studies predict loss rates of CFCs that are significantly larger in the tropics compared to midlatitudes (e.g. Rowland and Molina, 1975; Plumb and Ko, 1992; Douglass et al., 2008).

Not all long-lived halocarbons show such a characteristic behaviour in different stratospheric regions. In Fig. 2 the FRFs of $\mathrm{CHF}_{2} \mathrm{Cl}$ (HCFC-22) are depicted. HCFC-22 decomposes very slowly compared to CFC-11 and thus its FRF correlation with mean age is comparable for different stratospheric regions. The corresponding correlation function derived by Newman et al. (2006) is comparable with the one derived here. The primary sink of HCFC-22 is the reaction with $\mathrm{OH}$. The more uniform distribution of $\mathrm{OH}$ in the stratosphere then leads to a less variable vertical distribution of loss as compared to compounds with loss primarily due to absorption of radiation. Little variability with latitude can also be observed for compounds with very long stratospheric lifetimes in general (e.g. CFC-114, see Fig. 3) because the differences in photochemical loss are smaller than the measurement and calculation uncertainties.

To quantify the observed latitudinal differences polynomials were derived which allow the calculation of tropical FRFs from the mean age of air (see Figs. 1-6 and Table 2). The order of the polynomial was increased stepwise. If the corresponding Pearson correlation coefficient did not increase significantly (less than $\approx 0.05$ ) the polynomial with the lower order was chosen in most cases. A second visual criterion was the agreement of the curve for older ages as the data set is weighted towards younger ages.

In general, good agreement with the correlation functions derived by Newman et al. (2006) was found for lower ages of air (up to 0.5-2 years depending on the individual compound). This agrees with other observations indicating strong transport from the lower tropical stratosphere (below potential temperatures of about $450 \mathrm{~K}$ ) into the extra-tropics (Rosenlof et al., 1997). For older ages most compounds were found to decompose faster in the tropics than in the extratropics. The only exceptions were halocarbons with low stratospheric decomposition rates which showed comparable or even slightly lower FRFs: HCFC-22, HCFC-142b, CFC-115 and CFC-114. Two compounds, CFC-114a and HCFC-124, could not be compared as no functions for these compounds were derived by Newman et al. (2006).

FRFs can be assumed to be constant in time for a given mean age-of-air (e.g. Newman et al., 2007) but depend on the respective stratospheric region. Therefore the derived tropical correlation functions of FRFs vs mean age can be used for a wider temporal range than mixing ratio correlation functions and are valid as long as there are no major changes to general stratospheric circulation and composition. The limitations of these correlations lie in the temporal and spatial span of the available data set. Schoeberl 


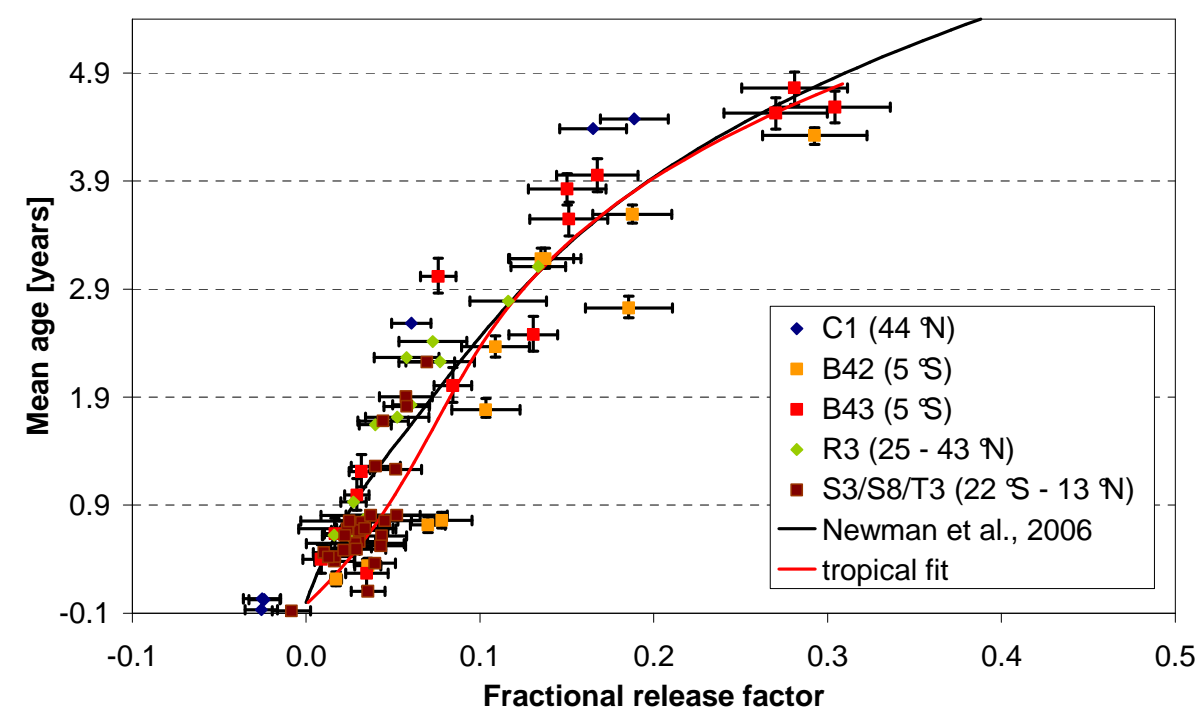

Fig. 2. The same as in Fig. 1 but for HCFC-22. This compound is found to decompose very slowly in the stratosphere. Thus, its FRFmean-age correlation is less influenced by different transport pathways or radiation and shows no differences for stratospheric regions that are separated by transport barriers.

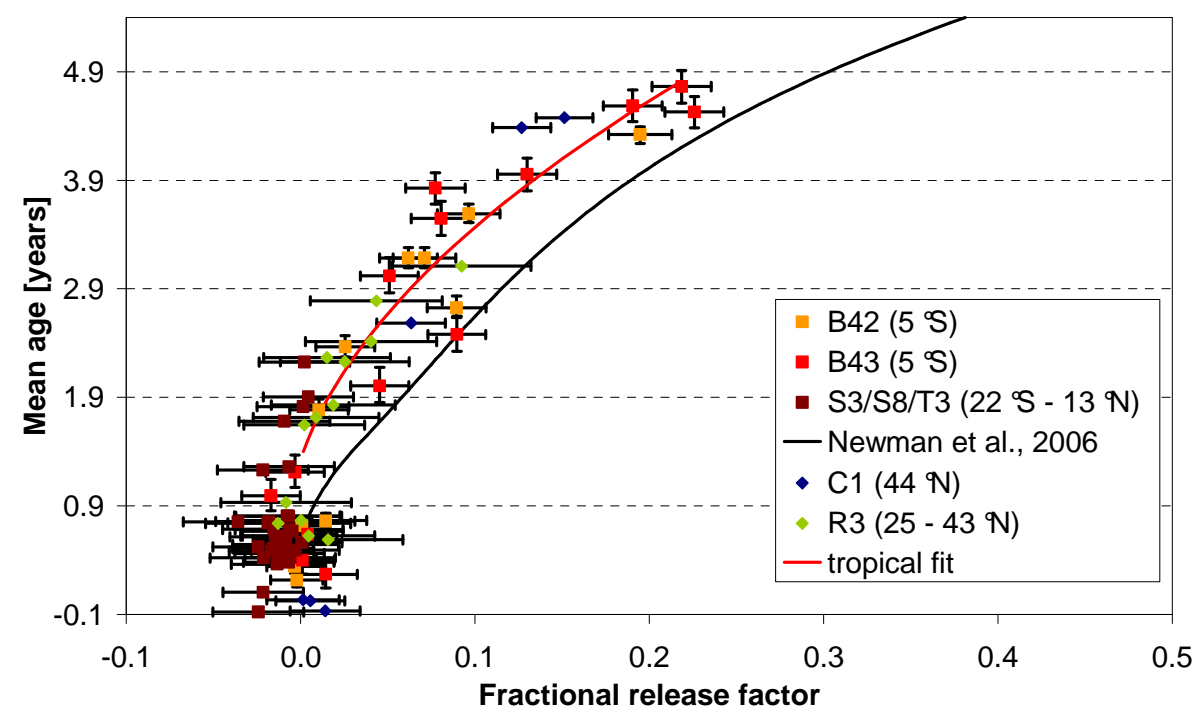

Fig. 3. The same as in Fig. 1 but for CFC-114. The observed tropical FRF values are slightly lower than those derived by Newman et al. (2006) for mid- and high latitudes.

et al. (2008) presented evidence for an influence of the annual oscillation (AO) as well as the quasi-biennial oscillation (QBO) on stratospheric trace gas distributions in the tropical stratosphere from satellite observations. This could potentially change correlations depending on the phase of the respective oscillations. Further studies are necessary to quantify these impacts on long-lived halocarbons in the tropics as well as in higher latitudes.

For the semi-empirical calculation of ODPs averaged FRF values are used (Daniel and Velders, 2007). Moreover, these values are calculated relative to the averaged FRF of CFC-11. Table 3 shows a comparison of these WMO values (which are mainly those derived by Daniel et al., 1995) with the relative tropical FRFs averaged for all ages between 2 and 4.8 years. The latter were derived according to a method described in Schauffler et al. (2003) and are thus comparable. The error bars represent the variability of the relative FRFs over the averaged mean age range. Most of the compounds were observed to decompose relatively quickly with increasing mean age in the tropics. Because the ratio of this 

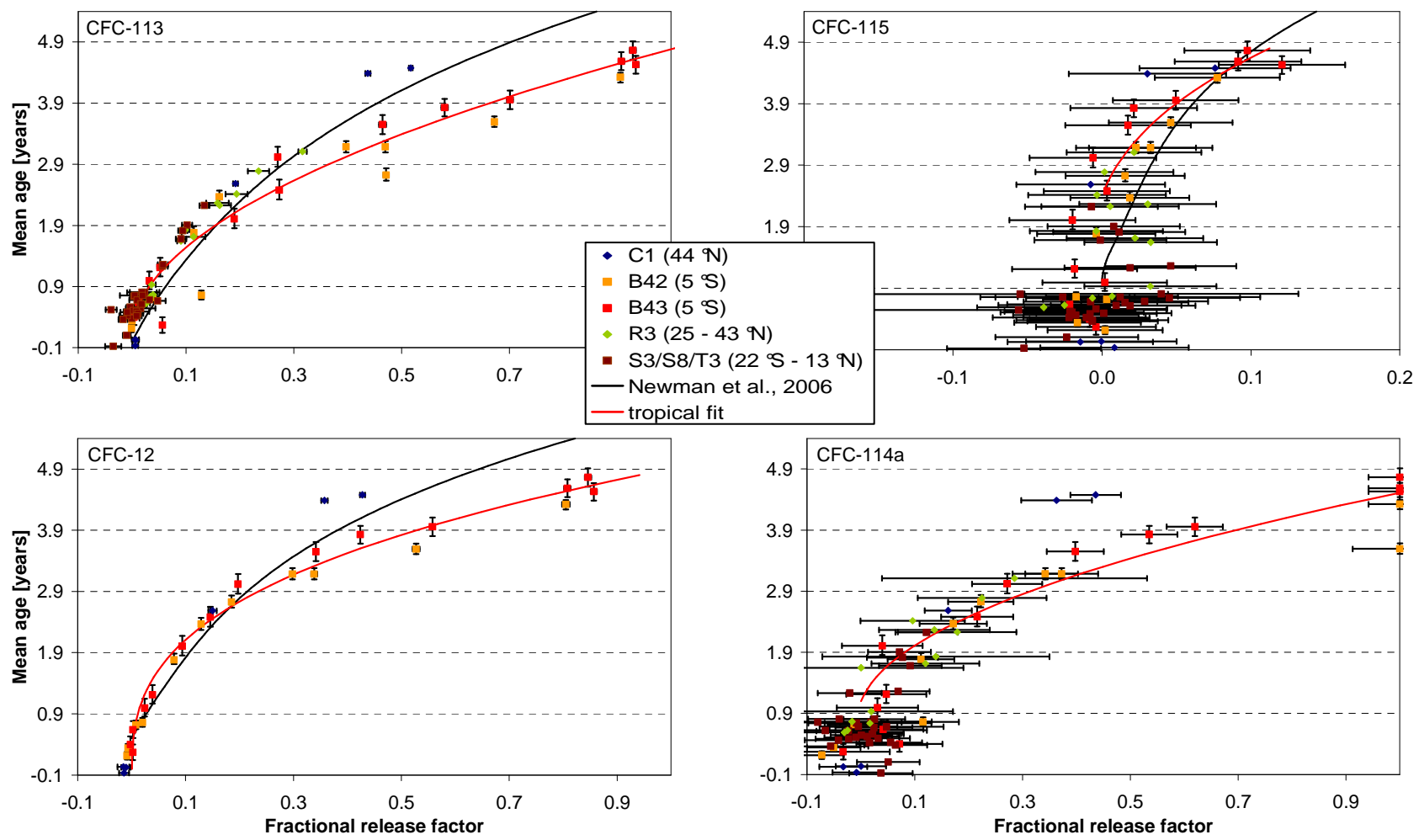

Fig. 4. The same as in Fig. 1 but for the CFCs CFC-12, CFC-113, CFC-114a and CFC-115.
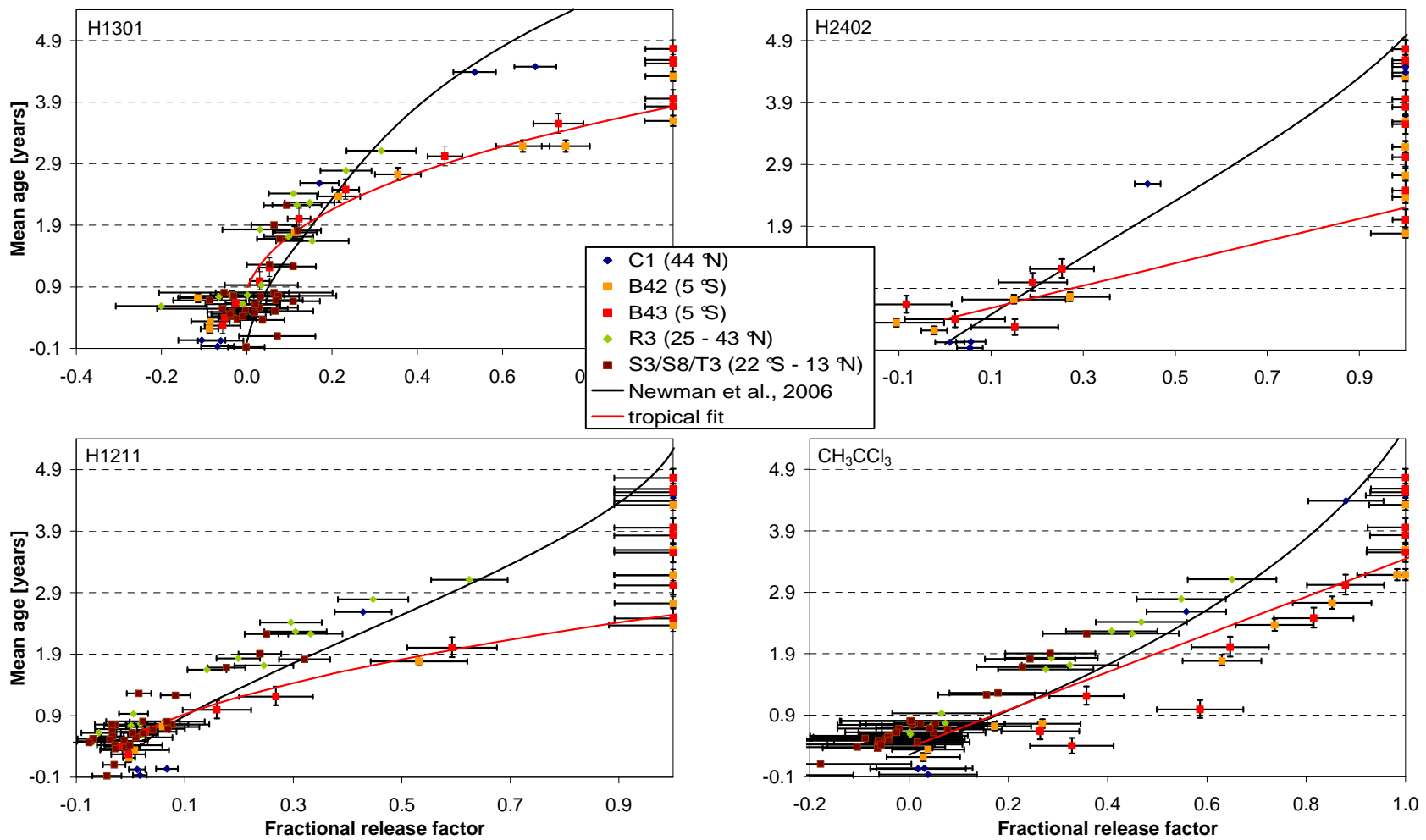

Fig. 5. The same as in Fig. 1 but for the Halons 1301, 1211 and 2402 as well as methyl chloroform. 

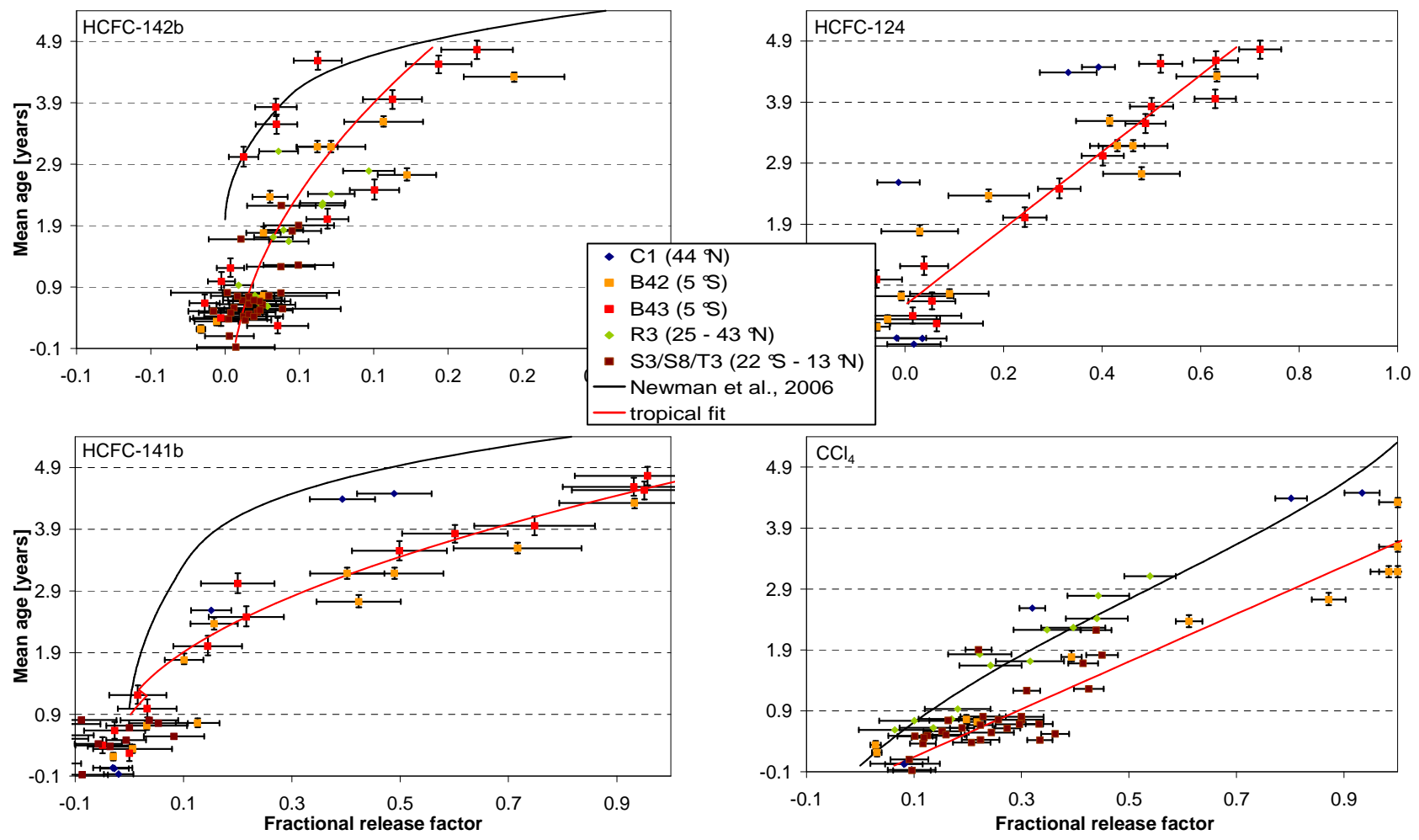

Fig. 6. The same as in Fig. 1 but for the HCFCs 142 b, 141 b and 124 as well as carbon tetrachloride.

decomposition relative to that of CFC-11 is not constant a high variability is introduced when the FRFs are averaged over a wide mean age range. Consistently most of the relative FRF means agree with those of the WMO within this uncertainty criterion. However, four compounds were found to have significantly different relative mean FRFs in the tropics. Halon 2402 showed a larger relative mean FRF which is caused by its rapid decomposition; the compound is already depleted to values below detection limits at mean ages of two years. CFC-114, HCFC-22 and HCFC-142b showed lower relative mean FRFs in the tropics. For CFC-114 (see Fig. 3) the WMO used the averaged relative FRF of Schauffler et al. (2003) (i.e. $0.28 \pm 0.02$ ) but our calculations resulted in a tropical value which is lower by a factor of two $(0.14 \pm 0.09)$. This issue remains unresolved because CFC's are mainly destroyed by photolysis and reactions with $\mathrm{O}^{1} \mathrm{D}$ and thus they should decompose faster in the tropical stratosphere. However, the correlation of FRFs and mean ages for CFC-114 derived by Newman et al. (2006) agrees much better with our tropical data (see Fig. 3). The tropical values of HCFC22 and HCFC- $142 b$ derived here $(0.23 \pm 0.11$ and $0.12 \pm 0.07)$ agree with those of Schauffler et al. (2003) derived from midand high-latitudes $(0.29 \pm 0.02$ for HCFC-22 and $0.08 \pm 0.04$ for HCFC-142b) but disagree with the greater values used in Daniel and Velders (2007) (see Table 3).

\section{Conclusions}

The measured set of air samples originating from the lower and middle tropical stratosphere enabled characterisation of the vertical distribution of 15 long-lived halocarbons. The data were used to derive Fractional Release Factors (FRFs) and relate these to the mean age of air in this region of the atmosphere. The tropical FRFs were internally and externally compared with mid- and high-latitude FRFs. Characteristic differences were found for air masses which entered the stratosphere more than 0.5 to 2.5 years prior to sample collection (depending on the individual compound). The midlatitude FRFs were found to increase at a considerably lower rate with mean age than tropical FRFs for 9 out of 13 longlived halocarbons (CFC-114a and HCFC-124 could not be compared). Moreover, FRFs averaged over an age range were calculated relative to an average FRF of CFC-11. They were compared with averaged values originating from observations in the mid- and high-latitude stratosphere which are currently used by the World Meteorological Organization for the semi-empirical calculation of Ozone Depletion Potentials (ODPs). Most values were in agreement though highly variable in the tropics. Therefore the ODPs calculated by the WMO (based on FRFs calculated by Daniel et al., 1995) can be considered as globally representative, with the exceptions of CFC-114, HCFC-22 and HCFC-142b. Our data suggests that the fractional release of these three compounds should 
Table 2. Correlation functions to derive FRFs of long-lived halocarbons from the mean age of air in the lower and middle tropical stratosphere (between $22^{\circ} \mathrm{N}$ and $22^{\circ} \mathrm{S}$ and above $360 \mathrm{~K}$ potential temperature). The polynomials of the form $y=a+b x+c x^{2}+d x^{3}$ are only valid for the given $\operatorname{FRF}(y)$ and mean age $(x)$ ranges. If a function is not valid down to a mean age of 0.0 this means the FRF is negligible in the corresponding lower stratospheric region. $R^{2}$ is the Pearson correlation coefficient.

\begin{tabular}{|c|c|c|c|c|c|c|}
\hline Compound & $a$ & $b$ & $c$ & $d$ & $R^{2}$ & $\begin{array}{l}\text { Validity ranges } \\
\text { (FRF \& mean age } \\
\text { in years) }\end{array}$ \\
\hline CFC-12 & 0.001 & -0.0013 & 0.00880 & 0.006733 & 0.98 & $\begin{array}{c}0.00-0.94 \\
0.0-4.8\end{array}$ \\
\hline CFC-11 & 0.019 & -0.1562 & 0.23586 & -0.033757 & 0.99 & $\begin{array}{c}0.0-1.0 \\
0.6-4\end{array}$ \\
\hline CFC-113 & -0.004 & -0.0008 & 0.04406 & 0 & 0.97 & $\begin{array}{l}0.0-1.0 \\
0.3-4.8\end{array}$ \\
\hline CFC-114 & -0.008 & -0.0100 & 0.01185 & 0 & 0.93 & $\begin{array}{c}0.0-0.22 \\
1.4-4.8\end{array}$ \\
\hline CFC-115 & 0 & -0.0078 & -0.00003 & 0.001364 & 0.66 & $\begin{array}{c}0.0-0.11 \\
2.5-4.8\end{array}$ \\
\hline CFC-114a & 0.043 & -0.1193 & 0.07352 & 0 & 0.90 & $\begin{array}{c}0.0-1 \\
1.1-4.6\end{array}$ \\
\hline HCFC-22 & 0.001 & 0.0655 & -0.01946 & 0.003991 & 0.92 & $\begin{array}{c}0.0-0.31 \\
0.0-4.8\end{array}$ \\
\hline HCFC-141b & -0.036 & 0.0012 & 0.04664 & 0 & 0.96 & $\begin{array}{l}0.0-1.0 \\
0.9-4.7\end{array}$ \\
\hline HCFC-142b & 0.007 & 0.0077 & 0.00414 & 0 & 0.66 & $\begin{array}{c}0.0-0.14 \\
0.0-4.8\end{array}$ \\
\hline HCFC-124 & -0.091 & 0.1590 & 0 & 0 & 0.92 & $\begin{array}{l}0.0-0.7 \\
0.6-4.8\end{array}$ \\
\hline $\mathrm{CCl}_{4}$ & 0.063 & 0.2557 & 0 & 0 & 0.92 & $\begin{array}{l}0.0-1.0 \\
0.0-3.7\end{array}$ \\
\hline $\mathrm{CH}_{3} \mathrm{CCl}_{3}$ & 0.121 & 0.3479 & 0 & 0 & 0.73 & $\begin{array}{l}0.0-1.0 \\
0.4-3.5\end{array}$ \\
\hline H-1211 & -0.069 & 0.0475 & 0.14664 & 0 & 0.97 & $\begin{array}{l}0.0-1.0 \\
0.6-2.6\end{array}$ \\
\hline H-1301 & -0.003 & -0.0381 & 0.03902 & 0.010271 & 0.96 & $\begin{array}{l}0.0-1.0 \\
0.9-3.8\end{array}$ \\
\hline H-2402 & -0.223 & 0.5555 & 0 & 0 & 0.88 & $\begin{array}{l}0.0-1 \\
0.4-2\end{array}$ \\
\hline
\end{tabular}

be reassessed for the non-tropical stratosphere where most ozone loss occurs. Daniel et al. (1995) assumed for simplification, that all tracer-tracer-correlation functions relative to CFC-11 are linear and thus the FRFs relative to CFC-11 are valid throughout the stratosphere. However, this simplification was found not to hold in the tropical stratosphere. Averaged FRFs relative to CFC-11 calculated accordingly are highly imprecise and thus questionable. For improved ODP calculations the FRF correlations with mean age as derived by Schauffler et al. (2003), Newman et al. (2006) and in this work should be used. Further, we present FRFs for CFC115 and CFC-114a which are not available in the respective literature (Daniel and Velders, 2007).

For the first time correlations of the FRFs of a set of 15 halocarbons were calculated as functions of the mean age of air for the lower and middle tropical stratosphere. These correlations can be considered as time-independent and are recommended for the parameterisation of models in order to reassess the chemical composition and the radiative balance in this region. For instance a recent model comparison by
Table 3. Comparison of averaged FRFs relative to the averaged FRF of $\mathrm{CFCl}_{3}$ (CFC-11) in the tropics with current WMO values that are based on observations at mid and high latitudes (see Table 81 of Daniel and Velders, 2007). The stated tropical errors do not include measurement or calculation uncertainties but represent only the $1 \sigma$ variability of the FRF within the mean age range used for averaging. The bold numbers are significantly different from those presented in Daniel and Velders (2007).

\begin{tabular}{lcc}
\hline Compound & $\begin{array}{c}\text { tropical mean FRF } \\
\text { relative to CFC-11* }\end{array}$ & $\begin{array}{c}\text { mean FRF relative to CFC-11 } \\
\text { (from Daniel and Velders, 2007) }\end{array}$ \\
\hline CFC-12 & $0.56 \pm 0.38$ & 0.60 \\
CFC-11** & $0.74 \pm 0.28$ & 0.55 \\
CFC-113 & $0.72 \pm 0.39$ & 0.75 \\
CFC-114 & $\mathbf{0 . 1 4} \pm \mathbf{0 . 0 9}$ & $0.28 \pm 0.02$ \\
CFC-115 & $0.05 \pm 0.06$ & n.a. \\
CFC-114a & $0.69 \pm 0.51$ & n.a. \\
HCFC-22 & $\mathbf{0 . 2 3} \pm \mathbf{0 . 1 1}$ & 0.35 \\
HCFC-141b & $0.76 \pm 0.41$ & 0.72 \\
HCFC-142b & $\mathbf{0 . 1 2} \pm \mathbf{0 . 0 7}$ & 0.36 \\
HCFC-124 & $0.64 \pm 0.20$ & 0.52 \\
CH ${ }_{3}$ CCl & $1.21 \pm 0.25$ & 1.08 \\
CCl & $1.14 \pm 0.31$ & 1.06 \\
H-1211 & $1.26 \pm 0.28$ & 1.18 \\
H-1301 & $0.90 \pm 0.49$ & 0.62 \\
H-2402 & $\mathbf{1 . 3 6} \pm \mathbf{0 . 0 0}$ & 1.22 \\
\hline
\end{tabular}

* Averaged for mean ages between 2.0 to 4.8 years.

* CFC-11: absolute averaged FRF is given.

n.a.: Not available, model derived values were used for ODP calculations.

Douglass et al. (2008) came to the conclusion that evaluations of halocarbon lifetimes "should include comparisons of both mean age and fractional release to interpret differences among models". Changes to these quantities could be of interest to policy makers as they influence not only the ODPs but also the Global Warming Potential (GWP) values (via Radiative Forcing values) which are currently assigned to the corresponding halocarbons. For further refinements of FRFs studies are needed to assess the influence of temporal and spatial stratospheric variations such as the quasi-biennial oscillation.

Acknowledgements. The work of Ingeborg Levin (University of Heidelberg), the CNES balloon team, the Geophysica team, the NOAA-ESRL GMD teams (who provided global tropospheric data) and of the anonymous referees is much appreciated. Furthermore we thank the European Space Agency, the Deutsches Zentrum fuer Luft- und Raumfahrt (project 50EE0016), the European Union (SCOUT-O3 project GOCE-CT-2003-505390), the Deutsche Forschungsgesellschaft (CAWSES project EN 367/4) as well as the British Natural Environment Research Council for funding.

Edited by: N. Harris 


\section{References}

Allen, N. D. C., Bernath, P. F., Boone, C. D., Chipperfield, M. P., Fu, D., Manney, G. L., Oram, D. E., Toon, G. C., and Weisenstein, D. K.: Global carbon tetrachloride distributions obtained from the Atmospheric Chemistry Experiment (ACE), Atmos. Chem. Phys., 9, 7449-7459, 2009, http://www.atmos-chem-phys.net/9/7449/2009/.

Boering, K. A., Daube Jr., B. C., Wofsy, S. C., Loewenstein, M., Podolske, J. R., and Keim, E. R.: Tracer-tracer relationships and lower stratospheric dynamics: $\mathrm{CO}_{2}$ and $\mathrm{N}_{2} \mathrm{O}$ correlations during SPADE, Geophys. Res. Lett., 21, 2567-2570, 1994.

Brasseur, G. and Solomon, S.: Aeronomy of the middle atmosphere, 2nd edition, Kluwer Academic Publishers Group, Dordrecht, Holland, 1986.

Clerbaux, C., Cunnold, D. M., Anderson, J., et al.: Halogenated Long-lived Compounds, Scientific assessment of ozone depletion: 2006, Global Ozone Research and Monitoring Project Report No. 50, Chapter 1, World Meteorological Organization, Geneva, 2007.

Daniel, J. S., Solomon, S., and Albritton, D. L.: On the evaluation of halocarbon radiative forcing and global warming potentials, J. Geophys. Res., 100, 1271-1285, 1995.

Daniel, J. S., Velders, G. J. M., Douglass, A. R., Forster, P. M. D., Hauglustaine, D. A., Isaksen, I. S. A., Kuijpers, L. J. M., McCulloch, A., and Wallington, T. J.: Halocarbon scenarios, ozone depletion potentials, and global warming potentials, Chapter 8 in World Meteorological Organization: Scientific assessment of ozone depletion: 2006, Global Ozone Research and Monitoring Project - Report No. 50, Geneva, 2007.

Douglass, A. R., Stolarski, R. S., Schoeberl, M. R., Jackman, C. H., Gupta, M. L., Newman, P. A., Nielsen, J. E., and Fleming, E. L.: Relationship of loss, mean age of air and the distribution of CFCs to stratospheric circulation and implications for atmospheric lifetimes, J. Geophys. Res., 113, D14309, doi:10.1029/2007JD009575, 2008.

Engel, A.: Untersuchungen zur Vertikalverteilung von Carbonylsulfid (COS) in der Stratosphäre, Dissertation, RheinischWestfälische Technische Hochschule Aachen, 1993.

Engel, A., Strunk, M., Müller, M., Haase, H.-P., Poss, C., Levin, I., and Schmidt, U.: Temporal development of total chlorine in the high-latitude stratosphere based on reference distributions of mean age derived from $\mathrm{CO}_{2}$ and $\mathrm{SF}_{6}$, J. Geophys. Res., 107(D12), 4136, doi:10.1029/2001JD000584, 2002.

Goldan, P. D., Kuster, W. C., Albritton, D. L., and Schmeltkopf, A. L.: Stratospheric $\mathrm{CFCl}_{3}, \mathrm{CF}_{2} \mathrm{Cl}_{2}$, and $\mathrm{N}_{2} \mathrm{O}$ height profile measurements at several latitudes, J. Geophys. Res., 85, 413-423, 1980.

Hall, T. M. and Plumb, R. A.: Age as a diagnostic of stratospheric transport, J. Geophys. Res., 99, 1059-1070, 1994.

Kaiser, J., Engel, A., Borchers, R., and Röckmann, T.: Probing stratospheric transport and chemistry with new balloon and aircraft observations of the meridional and vertical $\mathrm{N}_{2} \mathrm{O}$ isotope distribution, Atmos. Chem. Phys., 6, 3535-3556, 2006, http://www.atmos-chem-phys.net/6/3535/2006/.

Ko, M. K. W., Poulet, G., Blake, D. R., et al.: Very short-lived halogen and sulphur substances, Chapter 2 in Scientific Assessment of Ozone Depletion: 2002, Global Ozone Research and Monitoring Project - Report No. 47, Geneva, 2003.
Laube, J. C., Engel, A., Bönisch, H., Möbius, T., Worton, D. R., Sturges, W. T., Grunow, K., and Schmidt, U.: Contribution of very short-lived organic substances to stratospheric chlorine and bromine in the tropics - a case study, Atmos. Chem. Phys., 8, 7325-7334, 2008, http://www.atmos-chem-phys.net/8/7325/2008/.

Montzka, S. A., Fraser, P. J., Butler, J. H., et al.: Controlled substances and other source gases, Scientific assessment of ozone depletion: 2002, Global Ozone Research and Monitoring Project - Report No. 47, Chapter 1, World Meteorological Organization, Geneva, 2003.

Moore, D. P. and Remedios, J. J.: Growth rates of stratospheric HCFC-22, Atmos. Chem. Phys., 8, 73-82, 2008, http://www.atmos-chem-phys.net/8/73/2008/.

Newman, P. A., Nash, E. R., Kawa, S. R., Montzka, S. A., and Schauffler, S. M.: When will the Antarctic ozone hole recover?, Geophys. Res. Lett., 33, L12814, doi:10.1029/2005GL025232, 2006.

Newman, P. A., Daniel, J. S., Waugh, D. W., and Nash, E. R.: A new formulation of equivalent effective stratospheric chlorine (EESC), Atmos. Chem. Phys., 7, 4537-4552, 2007, http://www.atmos-chem-phys.net/7/4537/2007/.

Plumb, R. A. and Ko, M. K. W.: Interrelationships between mixing ratios of long-lived stratospheric constituents, J. Geophys. Res., 97, 10145-10156, 1992.

Plumb, R. A.: A “tropical pipe" model of stratospheric transport, J. Geophys. Res., 101, 3957-3972, 1996.

Plumb, R. A.: Stratospheric transport, J. Meteorol. Soc. Jpn., 80, 793-809, 2002.

Plumb, R. A.: Tracer interrelationships in the stratosphere, Rev. Geophys., 45, RG4005, doi:10.1029/2005RG000179, 2007.

Rinsland, C. P., Chiou, L., Boone, C., Bernath, P., and Mahieu, E.: First measurements of the HCFC-142b trend from atmospheric chemistry experiment (ACE) solar occultation spectra, J. Quant. Spectrosc. Ra., 110, 2127-2134, 2009.

Rosenlof, K. H., Tuck, A. F., Kelly, K. K., Russell, J. M., and McCormick, M. P.: Hemispheric asymmetries in water vapour and inferences about transport in the lower stratosphere, J. Geophys. Res., 102, 13213-13234, 1997.

Rowland, F. S. and Molina, M. J.: Chlorofluorocarbons in the environment, Rev. Geophys. Space Phys. 13, 1-35, 1975.

Schauffler, S. M., Heidt, L. E., Pollock, W. H., Gilpin, T. M., Vedder, J. F., Solomon, S., Lueb, R. A., and Atlas, E. L.: Measurements of halogenated organic compounds near the tropical tropopause, Geophys. Res. Lett., 20, 2567-2570, 1993.

Schauffler, S. M., Atlas, E. L., Blake, D. R., Flocke, F., Lueb, R. A., Lee-Taylor, J. M., Stroud, V., and Travnicek, W.: Distributions of brominated organic compounds in the troposphere and lower stratosphere, J. Geophys. Res., 104(D17), 21513-21535, 1999.

Schauffler, S. M., Atlas, E. L., Donnelly, S. G., Andrews, A., Montzka, S. A., Elkins, J. W., Hurst, D. F., Romashkin, P. A., Dutton, G. S., and Stroud, V.: Chlorine budget and partitioning during SOLVE, J. Geophys. Res., 108(D5), 4173, doi:10.1029/2001JD002040, 2003.

Schmidt, U., Kulessa, G., Klein, E., Röth, E.-P., Fabian, P., and Borchers, R.: Intercomparison of balloon borne cryogenic whole air samplers, Planet. Space Sci., 35, 647-656, doi:10.1016/00320633(87)90131-0, 1987. 
Schoeberl, M. R., Douglass, A. R., Newman, P. A., Lait, L. R., Lary, D., Waters, J., Livesey, N., Froidevaux, L., Lambert, A., Read, W., Filipiak, M. J., and Pumphrey, H. C.: QBO and annual cycle variations in tropical lower stratosphere trace gases from HALOE and Aura MLS observations, J. Geophys. Res., 113, D05301, doi:10.1029/2007JD008678, 2008.

Solomon, S., Tuck, A. F., Mills, M., Heidt, L. E., and Pollock, W. H.: On the evaluation of ozone depletion potentials, J. Geophys. Res., 97, 825-842, 1992.

Solomon, S. and Albritton, D. L.: Time-dependent ozone depletion potentials for short- and long-term forecasts, Nature 357, 33-37, doi:10.1038/357033a0, 1992.

Strunk, M., Engel, A., Schmidt, U., Wetter, T., Levin, I., and Glatzel-Mattheier, $\mathrm{H} .: \mathrm{CO}_{2}$ and $\mathrm{SF}_{6}$ as stratospheric age tracers: Consistency and the effect of mesospheric $\mathrm{SF}_{6}$-loss, Geophys. Res. Lett., 27, 341-344, 2000.
Volk, C. M., Elkins, J. W., Fahey, D. W., Sutton, G. S., Gilligan, J. M., Loewenstein, M., Podolske, J. R., Chan, K. R., and Gunson, M. R.: Evaluation of source gas lifetimes from stratospheric observations, J. Geophys. Res., 102(D21), 25543-25564, 1997.

Waugh, D. W., Hall, T. M., Randel, W. J., Rasch, P. J., Boville, B. A., Boering, K. A., Wofsy, S. C., Daube, B. C., Elkins, J. W., Fahey, D. W., Dutton, G. S., Volk, C. M., and Vohralik, P. F.: Three-dimensional simulations of longslived tracers using winds from MACCM2, J. Geophys. Res., 102(21), 493-513, 1997.

Waugh, D. W. and Hall, T. M.: Age of stratospheric air: Theory, observations, and models, Rev. Geophys., 40(4), 1010, doi:10.1029/2000RG000101, 2002. 